\title{
High-performance electron-transport-layer-free quantum junction solar cells with improved efficiency exceeding $10 \%$
}

Yuwen Jia, ${ }^{\dagger}, \#$ Haibin Wang, ${ }^{\ddagger}, \#$ Yinglin Wang, ${ }^{*}, \dagger$ Naoyuki Shibayama, ${ }^{\S}$ Takaya Kubo, ${ }^{\ddagger}$ Yichun Liu, ${ }^{\dagger}$ Xintong Zhang, ${ }^{*},{ }^{\dagger}$ Hiroshi Segawa*, ${ }^{*}, \S$

${ }^{\dagger}$ Center for Advanced Optoelectronic Functional Materials Research, and Key Laboratory of UV Light-Emitting Materials and Technology of Ministry of Education, Northeast Normal University, Changchun 130024, Jilin. P.R. China

Research Center for Advanced Science and Technology, The University of Tokyo, 153-8904 Tokyo, Japan

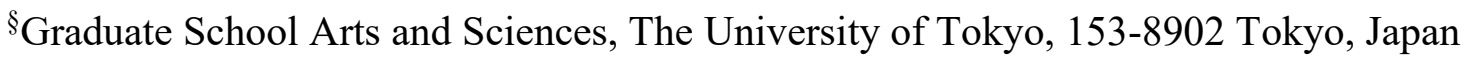

\# Y.J and H.W. contributed equally. 


\section{Experimental method}

Materials: Ammonium acetate (97.0\%), butylamine (Wako Special Grade, Reagent), znic acetate dehydrate (99\%), N, N-Dimethylformanide (DMF, Super Dehydrate, Reagent), toluene (Super Dehydrate, 99.50\%), octane (Wako Special Grade), acetone (Super Dehydrate) and acetonitrile (Super Dehydrate, 99.80\%) were purchased from Wako. Lead bromide $\left(\mathrm{PbBr}_{2}\right.$, for perovskite precursor, 99\%), lead iodide $\left(\mathrm{PbI}_{2}\right.$, for perovskite precursor, 99.99\%), 2Methoxyethanol (GR, >99.0\%), 2-Aminoethanol (GR, >99.0\%), 1,2-Ethanedithiol (>99.0\%), Oleic Acid (OA, $>85 \%)$ and 1-Octadecene (ODE, $>90.0 \%$ ) were purchased from TCI. Lead oxide $(\mathrm{PbO}, 100.00 \%)$ and Hexamethyldisilathiane ((TMS) $)_{2} \mathrm{~S}$, synthesis Grade) were purchased from Aldrich. Fluorine-doped tin oxide (FTO) glass with a sheet resistance of 10 ohm/square from Nippon sheet glass co. Ltd. was employed as transparent conductive substrate. All the chemicals were not reprocessed.

Solution phase ligand exchange method: The synthesis of oleic-acid-capped CQDs was same as previously studies. ${ }^{1}$ The ligand-exchanged precursor solution was prepared by dissolved $\mathrm{PbI}_{2}(0.1 \mathrm{M}), \mathrm{PbBr}_{2}(0.05 \mathrm{M})$ and acetate ammonium $(0.04 \mathrm{M})$ in $5 \mathrm{ml} \mathrm{DMF}$. Then mixing $5 \mathrm{ml}$ CQDs solution (octane, $10 \mathrm{mg} / \mathrm{ml}$ ) with the precursor solution. After stirring vigorously, the CQDs was completely transferred from octane to DMF. The ligand-exchanged solution was washed by octane 3 times, and precipitated by toluene and centrifuge. After drying by argon gas flow, the CQDs was dissolved by butylamine of $200 \mathrm{mg} / \mathrm{ml}$.

Preparation of the CQDSCs: FTO was ultrasonically cleaned three times by detergent, ultrapure water and ethanol, respectively. The sol-gel $\mathrm{ZnO}$ precursor solution was dissolved zinc 
acetate $(0.55 \mathrm{~g})$ and ethanol amine $(100 \mu \mathrm{l})$ in $10 \mathrm{ml}$ methanol. The precursor solution was spin-coated on FTO at $3000 \mathrm{rpm}$ for $30 \mathrm{~s}$, then annealed at $350{ }^{\circ} \mathrm{C}$. The $\mathrm{PbS}-\mathrm{PbI}_{2}$ solution was then spin-coated on the FTO or FTO/ZnO substrate at $1000 \mathrm{rpm}$ for $30 \mathrm{~s}$, following by an annealing on $80{ }^{\circ} \mathrm{C}$ hotplate in dry room. ${ }^{2}$ P-type CQDs was filmed by layer-by-layer method. $50 \mathrm{mg} / \mathrm{ml} \mathrm{CQDs} \mathrm{solution} \mathrm{was} \mathrm{spin-coated} \mathrm{at} 2500 \mathrm{rpm}$ for $15 \mathrm{~s}$. Then 1,2-Ethanedithiol (EDT) acetonitrile solution $(0.02 \mathrm{vol} \%)$ treated the film for $30 \mathrm{~s}$, followed by acetonitrile washing 3 times. Finally, $100 \mathrm{~nm} \mathrm{Au}$ was deposited as the electrode.

Ultraviolet photoelectron spectroscopy (UPS) equipped with He-I source $(h v=21.22 \mathrm{eV})$ (KRATOS Nova, Shimazu Co.) was used to determine the work function and Fermi level. The level of the samples was referred to that of Au which was in electrical contact with a sample. All measurements were performed under the same negative bias of $6 \mathrm{~V}$.

We estimated the Fermi level $\left(E_{\mathrm{F}}\right)$ and the valence band maximum $\left(E_{\mathrm{v}}\right)$ of PbS CQDs with respect to vacuum level using UPS (Figure S1a). The conduction band minimum $\left(E_{\mathrm{c}}\right)$ of $\mathrm{PbS}$ CQDs could be approximated through equation 1

$$
E_{c}=E_{v}-E_{g}=E_{v}-E_{g, o p t}-1.786 \frac{e^{2}}{4 \pi \varepsilon_{0} \varepsilon_{C Q D} R}
$$

where $e$ is elementary charge, $\varepsilon_{0}$ is vacuum permittivity, $R$ and $E_{\mathrm{g}, \mathrm{opt}}$ are the radius and optical bandgap of CQDs, respectively, and $\varepsilon_{\mathrm{CQD}}$ is the optical dielectric constant of CQD core material which in the used as 17.2 according the reported literature. ${ }^{3}$

Uv-visible near infrared absorption spectrum was measured by HITACHI U4150. 
space-charge-limited current (SCLC) measurement was measured by Keithley 2400 soure meter with an electron-type device $(\mathrm{FTO} / \mathrm{ZnO} / \mathrm{PbS} / \mathrm{Al})$. The electron mobility $\left(\mu_{\mathrm{e}}\right)$ can be calculated by

$$
J_{D}=\frac{9 \varepsilon_{C Q D} \varepsilon_{0} \mu V^{2}}{8 L^{3}}
$$

Where $L$ is the thickness of $\mathrm{PbS}$ films $(250 \mathrm{~nm})$. And the $n_{\text {trap }}$ can be calculated by

$$
n_{\text {trap }}=\frac{2 \varepsilon_{C Q D} \varepsilon_{0} V_{T F L}}{e L^{2}}
$$

The $V^{2}$ and $V_{\mathrm{TFL}}$ are shown in SCLC plot (Figure S2).

Scanning electron microscope images were captured through HITACHI SU8000.

Current density-voltage $(\boldsymbol{J}-\boldsymbol{V})$ characteristic was measured by Keithley 2401 soure meter under simulated $100 \mathrm{~mW} / \mathrm{cm}^{2}$, AM1.5G illumination (BUNKOKEIKI Otento-sun VI). The area of illumination was $0.049 \mathrm{~cm}^{2}$ with a $2.5 \mathrm{~mm}$ diameter photo mask, and the step of voltage was $5 \mathrm{mV}$.

External quantum efficiency (EQE) was BUNKOKEIKI CEP-2000. The area of illumination was $0.049 \mathrm{~cm}^{2}$, and the step of wavelength was $5 \mathrm{~nm}$.

Light intensity dependency of $J_{\mathrm{sc}}$ and $V_{\mathrm{oc}}$. We can analysis the exponential factor $(\alpha)$ from $J_{\mathrm{sc}}$ vs light intensity $(P)$ test, using the relational expression of $J_{\text {sc }} \propto P^{\alpha}$. The ideal factor (n) and reverse saturation current density $\left(J_{0}\right)$ can be expressed by

$$
V_{o c}=\frac{n k T}{q} \ln \left(\frac{J_{s c}}{J_{0}}\right)
$$


where $k$ is Boltzmann constant, $T$ is temperature, and $q$ is elementary charge.

Mott-schokttey measurement was measured by Modulab XM PhotoEchem station (Solartron Analytical). The frequence was $1000 \mathrm{~Hz}$, and the step of voltage was $5 \mathrm{mV}$.

The depletion width can be expressed by

$$
W_{D}=\frac{1}{N_{P}} \sqrt{\frac{2 \varepsilon \varepsilon_{0}\left(V_{b i}-V\right)}{q\left(\frac{1}{N_{p}}-\frac{1}{N_{n}}\right)}}
$$

where $N_{\mathrm{p}}$ and $N_{\mathrm{n}}$ are doping density of $\mathrm{PbS}-\mathrm{EDT}$ and $\mathrm{PbS}-\mathrm{PbI} 2, \varepsilon_{0}$ is vacuum dielectric constant, $\varepsilon$ is relative dielectric constant, and $V_{\text {bi }}$ is built in potential.

The doping density of $\mathrm{PbS}-\mathrm{EDT}$ and $\mathrm{PbS}-\mathrm{PbI}_{2}$, was measured by the capacitance-voltage $(C-V)$ curve (Figure $\mathrm{S} 3$ ). The structure of device was $\mathrm{FTO} / \mathrm{ZnO} / \mathrm{CQD} / \mathrm{Au}$, and the equation was

$$
\frac{1}{c^{2}}=\frac{2\left(V_{b i}-V\right)}{A^{2} q \varepsilon_{C Q D} \varepsilon_{0} N}
$$

where the $A$ was the area of electrode, $V_{\mathrm{bi}}$ was the built-in potential, and $N$ was the doping density of PbS-PbI $2\left(N_{\mathrm{PbS}-\mathrm{PbI} 2}\right)$ and PbS-EDT ( $\left.N_{\mathrm{PbS}-\mathrm{EDT}}\right)$. The calculated $N_{\mathrm{PbS}-\mathrm{Pb} 2}$ and $N_{\mathrm{PbS}-\mathrm{EDT}}$ are $1.13 \times 10^{16} \mathrm{~cm}^{-3}$ and $1.46 \times 10^{16} \mathrm{~cm}^{-3}$.

The variation of $\boldsymbol{J}_{\mathbf{s c}}$ and $\boldsymbol{V}_{\mathbf{o c}}$ as the function of light-soaking time was measured by Keithley 2400 soure meter under simulated $100 \mathrm{~mW} / \mathrm{cm}^{2}$, AM1.5G illumination (Enlitech, SS-F5-3A) in air ambient environment with the humidity of $30 \%$. 
Table S1. Previous works of the quantum junction solar cells.

\begin{tabular}{ccccc}
\hline Ref & Subject & Device structure & PCE \\
(\%)
\end{tabular}
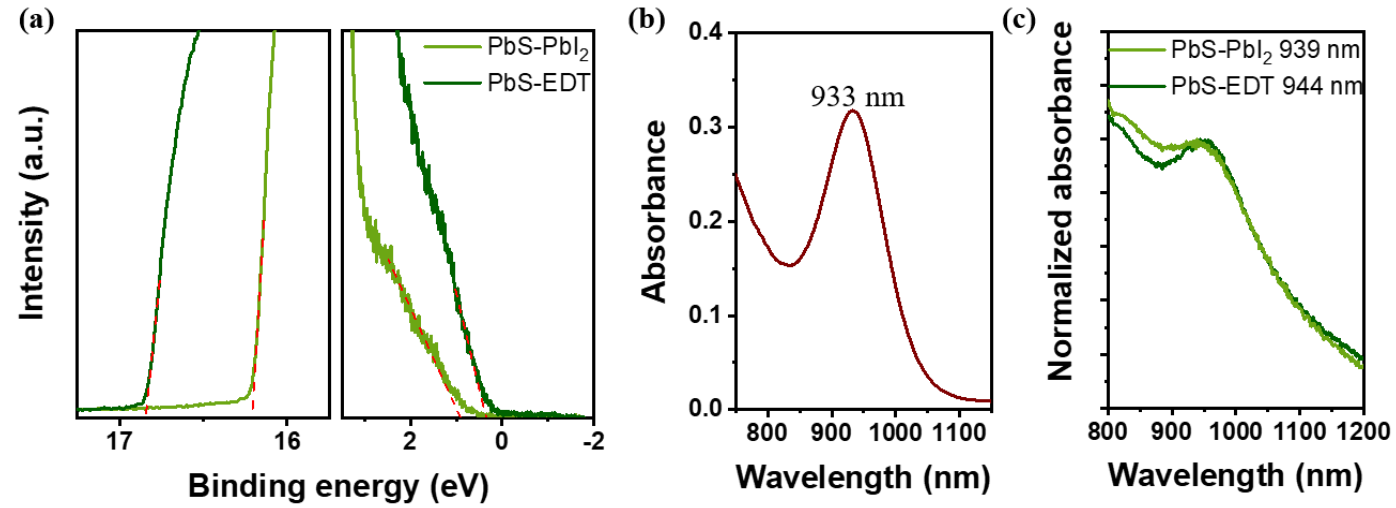

Figure S1. (a)UPS spectra of $\mathrm{PbS}-\mathrm{PbI}_{2}$ and PbS-EDT CQDs. The left side is the secondary electron cut-off region, and the right side is the near Fermi edge. (b) Absorbance spectrum of PbS-OA CQD in octane solution. (c) Normalized absorbance spectrum of $\mathrm{PbS}-\mathrm{PbI}_{2}$ and $\mathrm{PbS}-$ EDT films. 
Table S2. Energy levels of PbS-PbI 2 and PbS-EDT CQDs measured by UPS and ultravioletvisible spectroscopy test.

\begin{tabular}{cccccc}
\hline & $\begin{array}{c}E_{\mathrm{c}} \\
(\mathrm{eV})\end{array}$ & $\begin{array}{c}E_{\mathrm{V}} \\
(\mathrm{eV})\end{array}$ & $\begin{array}{c}E_{\mathrm{F}} \\
(\mathrm{eV})\end{array}$ & $\begin{array}{c}E_{\text {cutoff }} \\
(\mathrm{eV})\end{array}$ & $\begin{array}{c}E_{\mathrm{F}}-E_{\mathrm{V}} \\
(\mathrm{eV})\end{array}$ \\
\hline${\mathrm{PbS}-\mathrm{PbI}_{2}}$ & -4.54 & -5.91 & -5.01 & 16.21 & 0.90 \\
$\mathrm{PbS}-\mathrm{EDT}$ & -3.36 & -4.73 & -4.37 & 16.85 & 0.36 \\
\hline
\end{tabular}
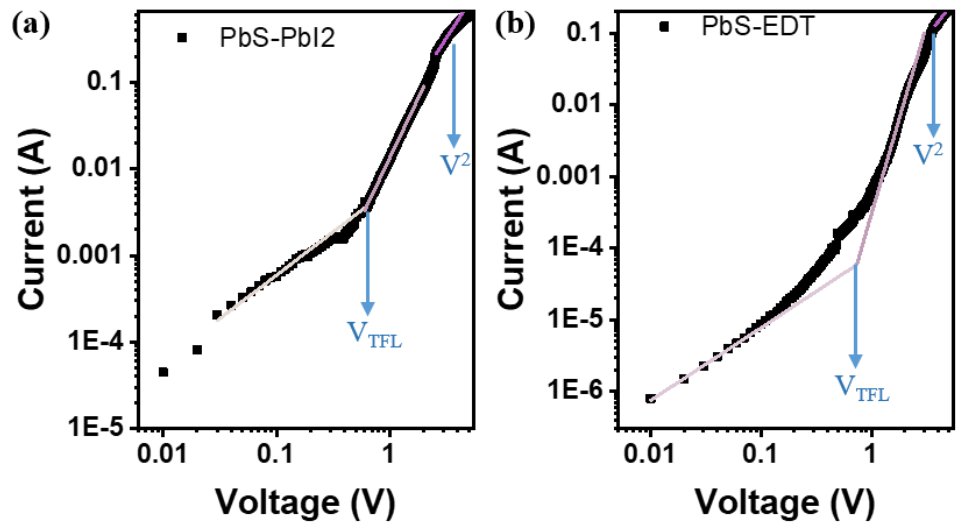

Figure S2. Space-charge-limited current (SCLC) plots of (a) $\mathrm{PbS}-\mathrm{PbI}_{2}$ and (b) $\mathrm{PbS}-\mathrm{EDT}$ film.
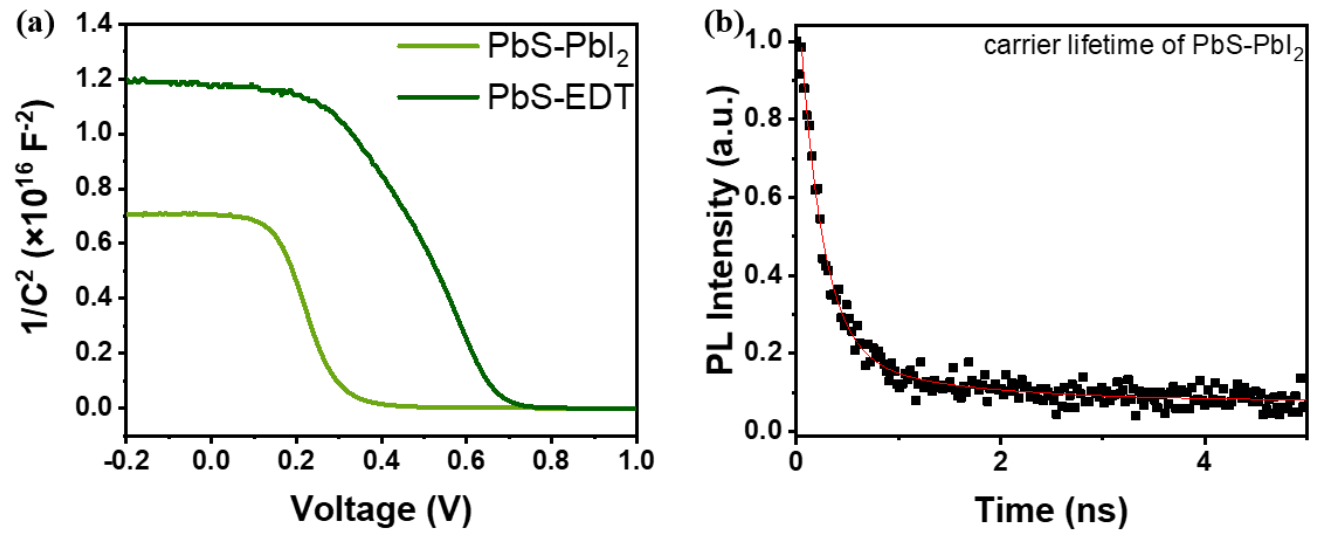

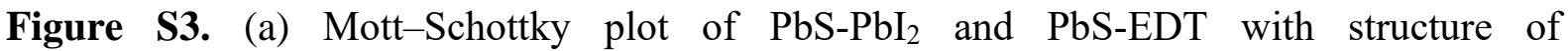
$\mathrm{FTO} / \mathrm{ZnO} / \mathrm{PbS} / \mathrm{Au}$. (b) PL decay trace of $\mathrm{PbS}-\mathrm{PbI}_{2}$ film. 
Table S3. Photoelectrical properties of the $\mathrm{PbS}-\mathrm{PbI}_{2}$ and $\mathrm{PbS}-\mathrm{EDT}$ films.

\begin{tabular}{ccccc}
\hline & $\begin{array}{c}\mu_{\mathrm{e}} \\
\left(\mathrm{cm}^{2} / \mathrm{V} \mathrm{S}\right)\end{array}$ & $\begin{array}{c}n_{\text {trap }} \\
\left(\mathrm{cm}^{-3}\right)\end{array}$ & $\begin{array}{c}N \\
\left(\mathrm{~cm}^{-3}\right)\end{array}$ & $\begin{array}{c}\tau \\
(\mathrm{ns})\end{array}$ \\
\hline $\mathrm{PbS}-\mathrm{PbI}_{2}$ & $2.77 \times 10^{-3}$ & $1.91 \times 10^{16}$ & $1.13 \times 10^{16}$ & 0.769 \\
$\mathrm{PbS}-\mathrm{EDT}$ & $7.76 \times 10^{-4}$ & $2.24 \times 10^{16}$ & $1.46 \times 10^{16}$ & \\
\hline
\end{tabular}

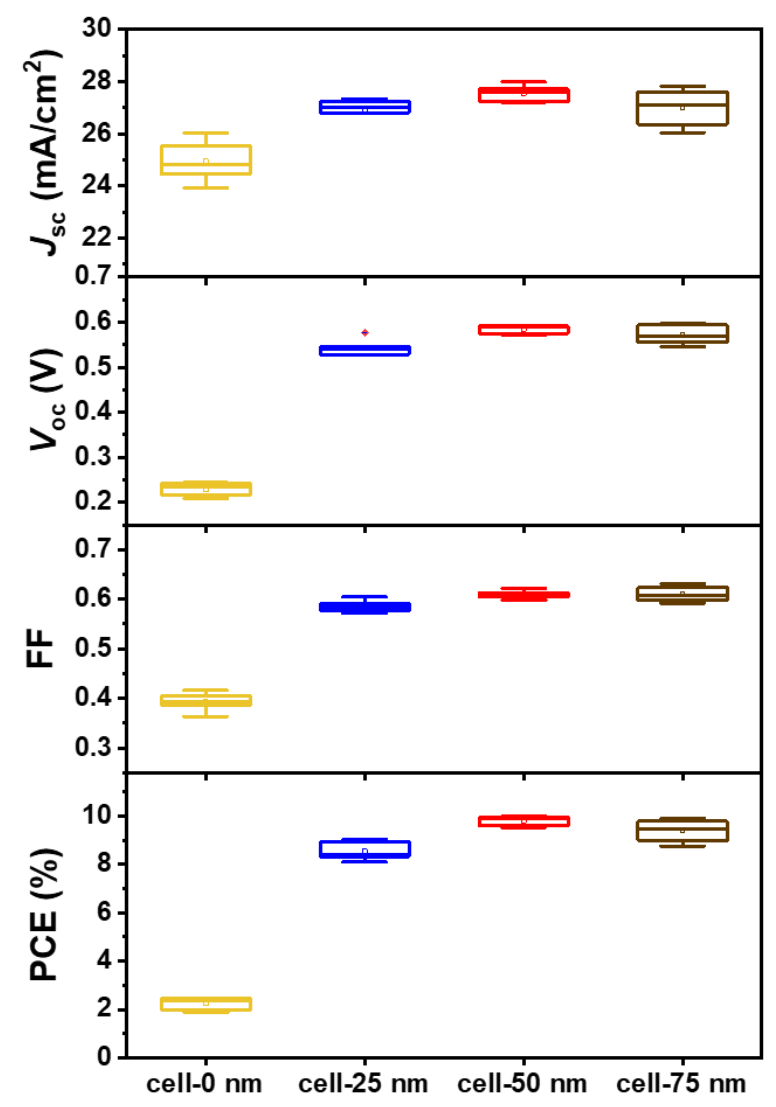

Figure S4. Performance parameters of QJSCs with different thickness of PbS-EDT. 

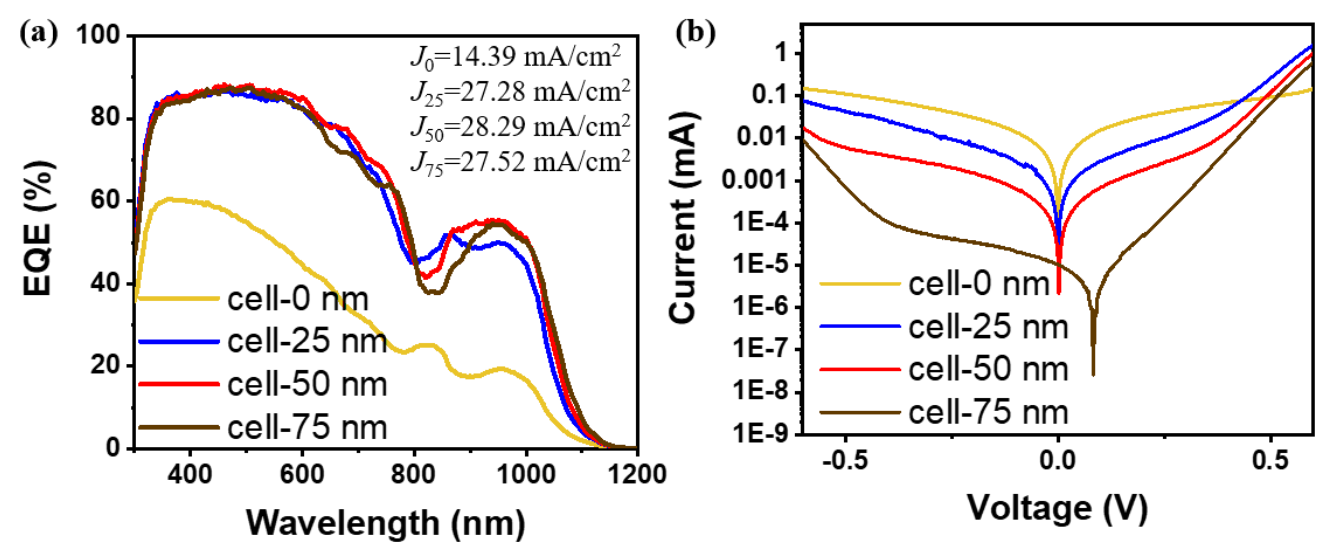

Figure S5. (a) EQE curves for devices with different thickness of $\mathrm{PbS}-\mathrm{PbI}_{2}$. (b) $J-V$ characteristics in the dark of these devices.

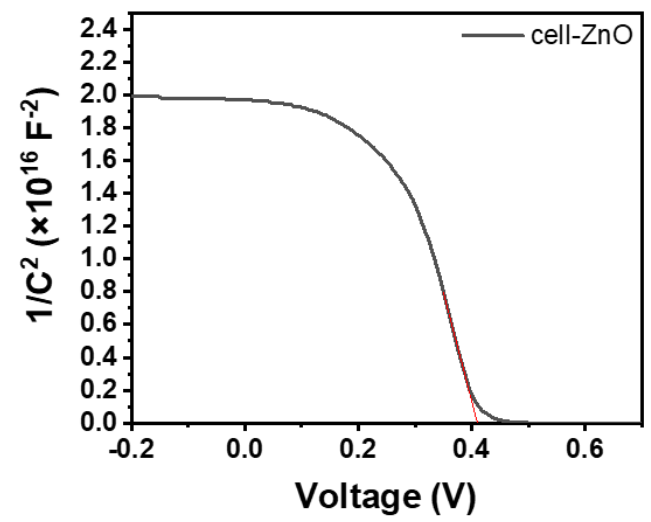

Figure S6. Mott-Schottky plot of cell-ZnO devices 


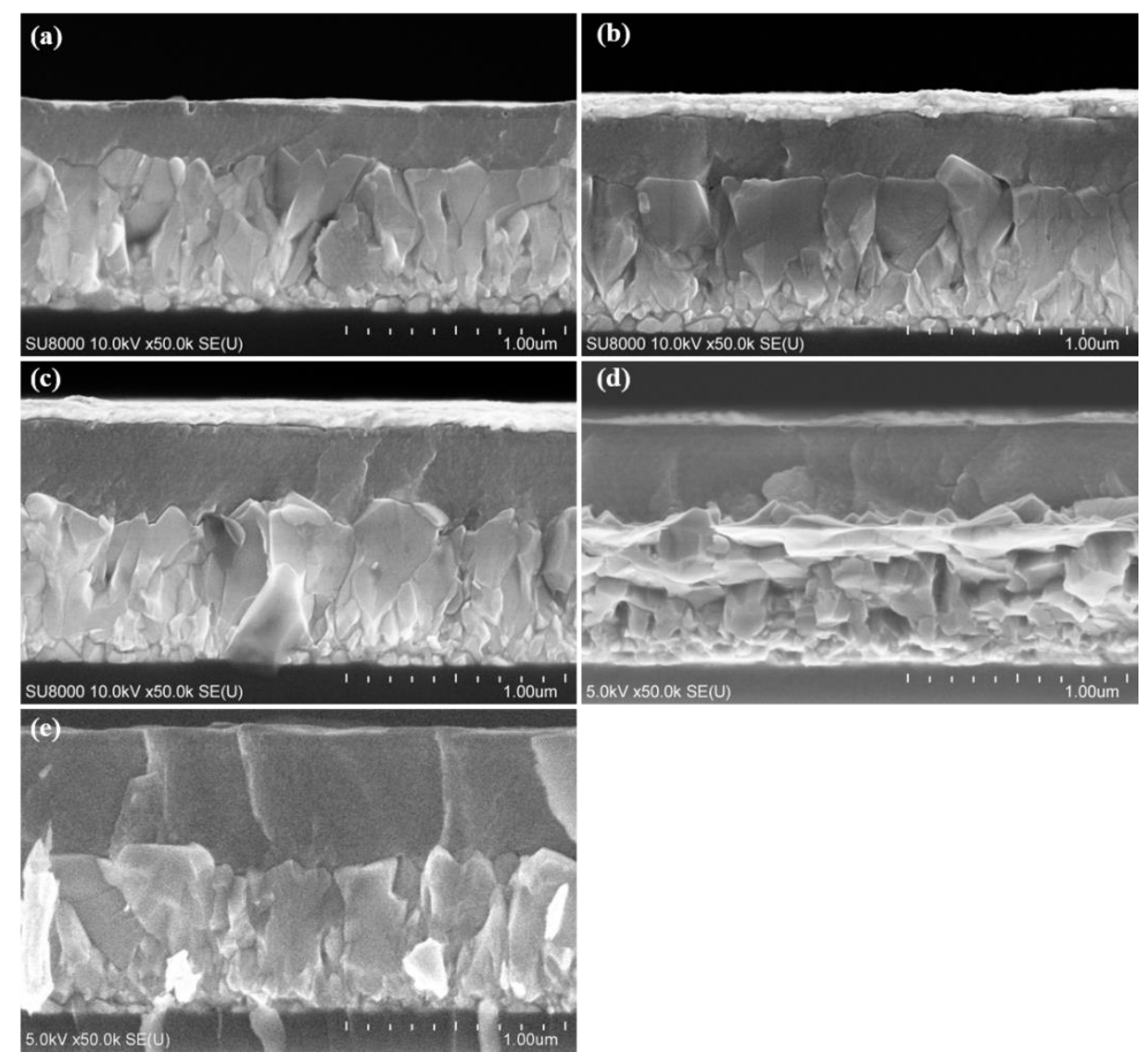

Figure S7. Cross-sectional SEM image of MOETL-free QJSCs with different thickness of $\mathrm{PbS}-\mathrm{PbI}_{2}$.

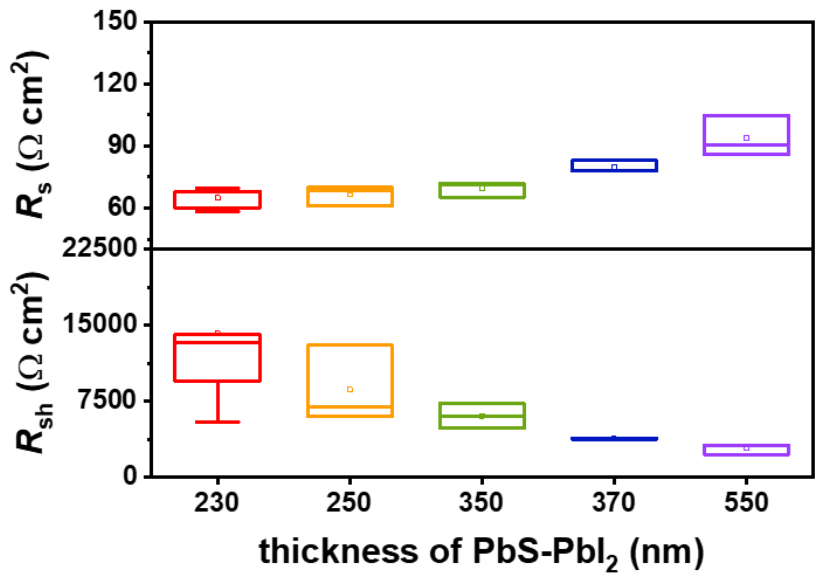

Figure S8. Series resistance $\left(R_{\mathrm{S}}\right)$ and shunt resistance $\left(R_{\mathrm{sh}}\right)$ for devices with different thickness of $\mathrm{PbS}-\mathrm{PbI}_{2}$ calculated by $\mathrm{J}-\mathrm{V}$ characteristics. 


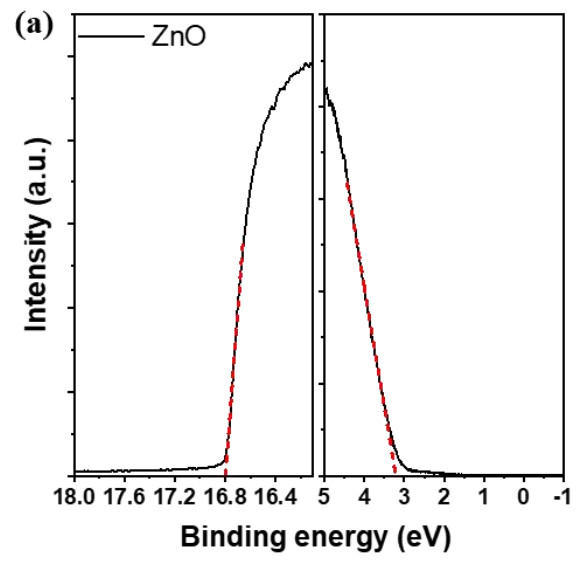

(b)
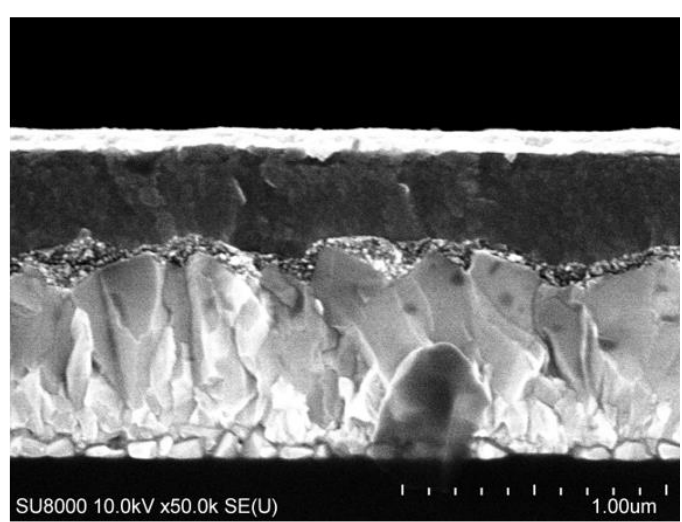

Figure S9. (a) Ultraviolet photoelectron spectroscopy (UPS) spectra of $\mathrm{ZnO}$. The left side is the secondary electron cut-off region, and the right side is the near Fermi edge. (b) Crosssectional SEM image of cell-ZnO device.

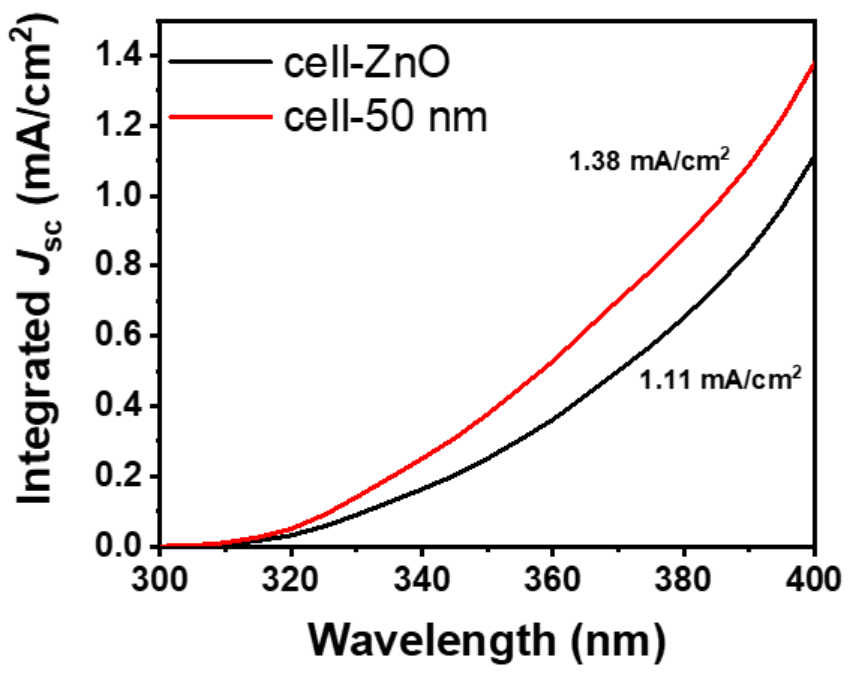

Figure S10. Enlarged EQE integrated current density image in the near ultraviolet region. 


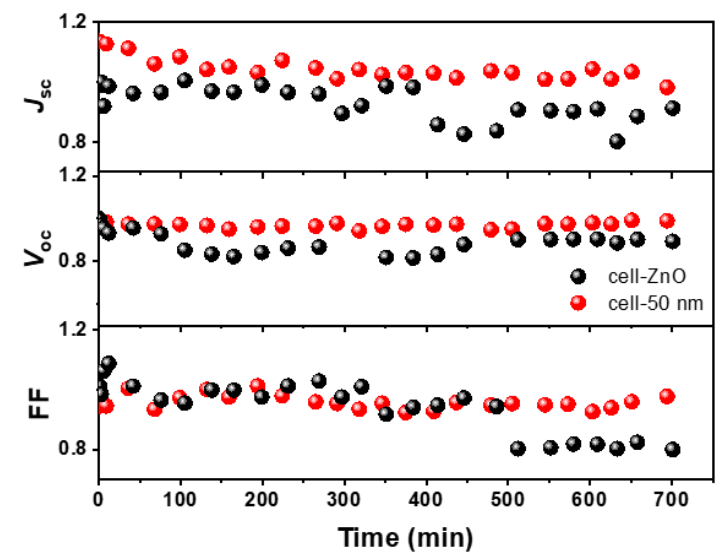

Figure S11. The $J_{\mathrm{sc}}, V_{\mathrm{oc}}$ and $\mathrm{FF}$ of cell- $\mathrm{ZnO}$ and cell-50 $\mathrm{nm}$ as function of time. This test was carried out under the AM1.5G illumination in air ambient environment with the humidity of $30 \%$ without temperature control.
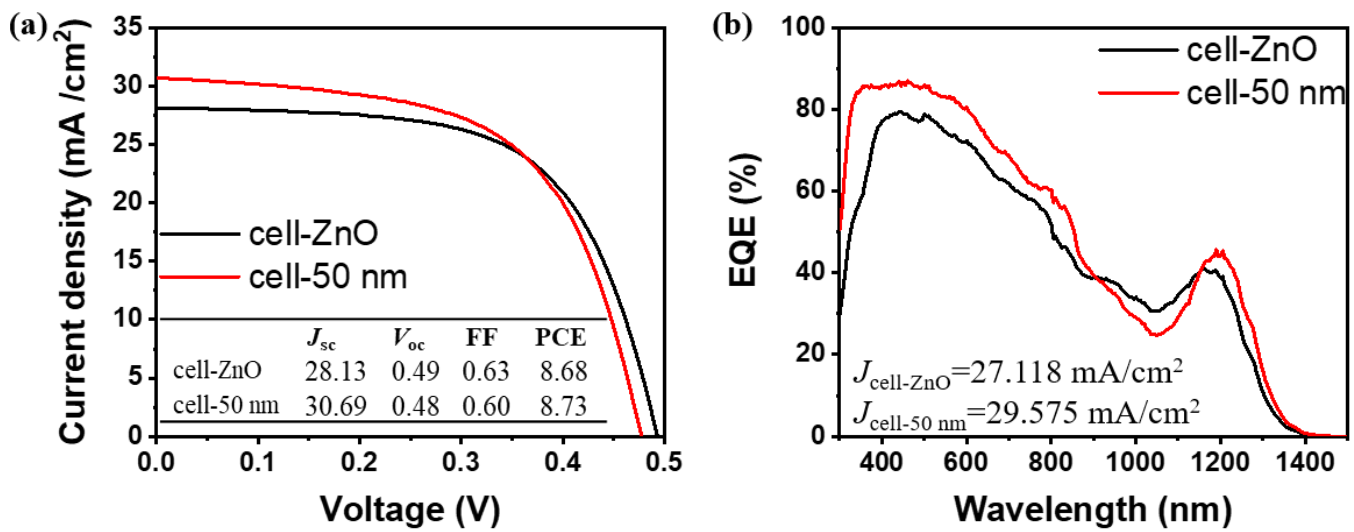

Figure S12. (a) $J-V$ characteristics of cell- $\mathrm{ZnO}$ and cell-50 $\mathrm{nm}$ devices, which were fabricated using infrared PbS QDs with absorption peak of $1200 \mathrm{~nm}$. (b) EQE curves of these devices. 


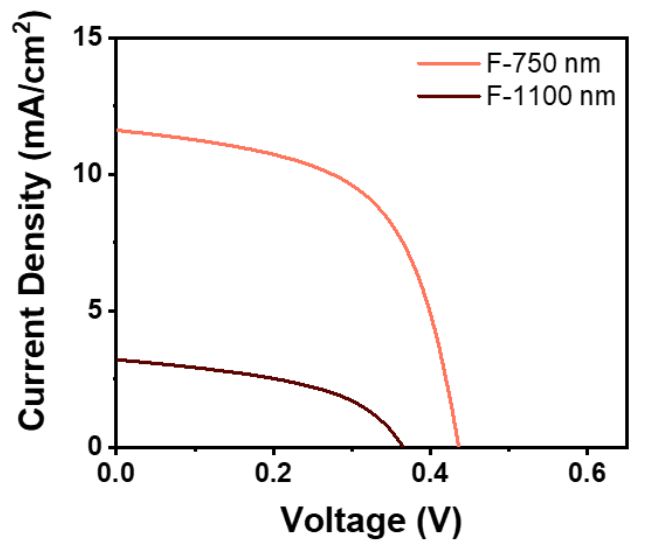

Figure S13. 750 and $1100 \mathrm{~nm}$ IR-filtered $J-V$ characteristics of MOETL-free QJSCs, which were fabricated using infrared $\mathrm{PbS}$ QDs with absorption peak of $1200 \mathrm{~nm}$.

Table S4. Performance parameters of the IR-filtered $J-V$ characteristics.

\begin{tabular}{c|c|c|c|c}
\hline & $\begin{array}{c}J_{\mathrm{sc}} \\
\left(\mathrm{mA} / \mathrm{cm}^{2}\right)\end{array}$ & $V_{\mathrm{oc}}(\mathrm{V})$ & FF & PCE (\%) \\
\hline $\mathrm{F}-750 \mathrm{~nm}$ & 11.62 & 0.436 & 0.580 & 2.93 \\
$\mathrm{~F}-1100 \mathrm{~nm}$ & 3.21 & 0.366 & 0.472 & 0.55 \\
\hline
\end{tabular}

\section{REFERENCES}

(1) Wang, H.; Kubo, T.; Nakazaki, J.; Segawa, H. Solution-Processed Short-Wave Infrared PbS Colloidal Quantum Dot/ZnO Nanowire Solar Cells Giving High Open-Circuit Voltage. ACS Energy Lett. 2017, 2, 2110-2117.

(2) Takahashi, A.; Wang, H.; Fukuda, T.; Kamata, N.; Kubo, T.; Segawa, H. AnnealingTemperature Dependent Carrier-Transportation in $\mathrm{ZnO} / \mathrm{PbS}$ Quantum Dot Solar Cells Fabricated Using Liquid-Phase Ligand Exchange Methods. Energies 2020, 13, 5037. 
(3) Brown, P. R.; Kim, D.; Lunt, R. R.; Zhao, N.; Bawendi, M. G.; Grossman, J. C.; Bulovic, V. Energy Level Modification in Lead Sulfide Quantum Dot Thin Films through Ligand Exchange. ACS Nano 2014, 8, 5863-5872.

(4) Tang, J.; Liu, H.; Zhitomirsky, D.; Hoogland, S.; Wang, X.; Furukawa, M.; Levina, L.; Sargent, E. H. Quantum Junction Solar Cells. Nano Lett. 2012, 12, 4889-4894.

(5) Liu, H.; Zhitomirsky, D.; Hoogland, S.; Tang, J.; Kramer, I. J.; Ning, Z.; Sargent, E. H. Systematic Optimization of Quantum Junction Colloidal Quantum Dot Solar Cells. Appl. Phys. Lett. 2012, 101, 151112.

(6) Ning, Z.; Ren, Y.; Hoogland, S.; Voznyy, O.; Levina, L.; Stadler, P.; Lan, X.; Zhitomirsky, D.; Sargent, E. H. All-Inorganic Colloidal Quantum Dot Photovoltaics Employing Solution-Phase Halide Passivation. Adv. Mater. 2012, 24, 6295-6299.

(7) Ning, Z.; Zhitomirsky, D.; Adinolfi, V.; Sutherland, B.; Xu, J.; Voznyy, O.; Maraghechi, P.; Lan, X.; Hoogland, S.; Ren, Y.; et al. Graded Doping for Enhanced Colloidal Quantum Dot Photovoltaics. Adv. Mater. 2013, 25, 1719-1723. 